\title{
O homem que calculava, de Malba Tahan (Um fenômeno de leitura literária na infoera)
}

\author{
The man who calculated, by Malba Tahan (A \\ literary reading phenomenon in infoera)
}

\author{
Divino José PINTO*
}

Resumo: O público jovem, cuja competência leitora está em formação, enfrenta crises contínuas, e na busca de tal competência tem à sua disposição instrumentos de mediação, como a televisão, a internet e outras mídias, verdadeiros facilitadores da recepção. Contudo, tais recursos são questionáveis quando se trata de leitura como fruição crítica. Propomos, então, abordar em O homem que calculava, romance de Malba Tahan, certas características e especificidades que funcionam como atrativos responsáveis pelo êxito alcançado por esse texto junto à juventude, num momento de suspensão de valores e reengenharia das habilidades ledoras.

\begin{abstract}
The young audience whose reading competence is in training, confront with continual crises, and in the pursuit of such competence has at its disposal mediation tools such as television, the internet and other media, which are true facilitators of receiption. However, such resources are questionable when it comes to reading as critical fruition. We propose to approach in The man who calculated, by Malba Tahan, certain features and characteristics that act as attractive responsible for the success achieved by this text by the youth, in a moment of suspension values and reengineering of reading skills.
\end{abstract}

Palavras-chave: Narrativa. Juventude. Leitura. Recepção. Êxito.

Keywords: Narrative. Youth. Reading. Reception. Success.

\footnotetext{
* Pontifícia Universidade Católica de Goiás.
} 


\section{Introdução}

O romance de Malba Tahan, em pauta, parece revelar certa propensão para o exótico presente na alma do brasileiro, principalmente no público jovem, concitando-nos literariamente a reflexões interessantes, uma vez que ele está permeado de questões de toda ordem: psicológica, cultural, histórica, identitária; apresentando-se a um só tempo como narrativa linear, em sua forma escrita, e narrativa complexa, na sua realização como escritura. É, na verdade, um romance mobilizador de interesses tanto individuais quanto coletivos e, para penetrarmos seu universo, é preciso considerar, além de sua temática e de suas imagens exuberantes, o frescor de sua linguagem aliado ao centramento da verossimilhança nele observável, que lhe confere caráter inusitado, que acreditamos compor o cerne de um conjunto de elementos e procedimentos que fazem desse romance uma paca sui generis na infoera.

A fim de realizarmos incursões sobre os temas elencados acima, nossa análise terá conformação didática, em tópicos breves, destacando, no próprio romance, partes que ilustrem e problematizem tais procedimentos para, finalmente, buscarmos uma unidade refletida em $O$ homem que calculava como obra literária narrativa dedicada a um público cada dia mais absorvido pelas novas mídias, mas que, de certo modo, contrariou muitas previsões e se estabeleceu como um grande fenômeno de leitura em um momento de reconfiguração de valores e hábitos.

\section{Contextualizando}

Situar historicamente o romance de Malba Tahan, O homem que calculava, é certamente uma tarefa desafiadora. A narrativa gira em torno da figura do calculista persa Beremiz Samir e se desenvolve em um ambiente próprio da antiga Arábia, tendo ao centro a bela Bagdá, berço de riqueza, cultura e ciência; num misto de aventura, filosofia, romance e, principalmente, muitas questões matemáticas, o que seria plenamente razoável, considerando ser Malba Tahan o pseudônimo do professor de matemática, Júlio César de Mello e Souza.

O homem que calculava faz vir à luz a beleza e a exuberância das terras e dos costumes árabes antigos, refletindo valores eternos de um povo que soube con- 
ciliar de maneira singular a tradição, a ciência e a religiosidade.

É nesse ambiente e num tempo remoto que Malba Tahan faz fluir uma história que cumpre a um só tempo a dupla façanha de envolver completamente o leitor enquanto realiza a apologia do raciocínio dirigido pela matemática, atribuindo aos números e à lógica um caráter lúdico bem diverso da aridez com a qual nos têm sido apresentadas as ciências exatas. É um ambiente no qual se pode encontrar, xeiques, xeques, vizires, princesas, camelos, mercadores, príncipes, reis e tantas outras figuras do universo árabe, com alusões constantes do mundo hindu, chegando até mesmo a mencionar a China lendária, a simbolizar, por extensão, todo o esplendor do Oriente.

Contudo, é importante salientar que, apesar da história estar ambientada nesse universo típico da Antiguidade árabe, a linguagem possui a fluência de um discurso moderno, uma vez que as palavras e expressões grafadas no original são acompanhadas de notas explicativas, proporcionando ao aventureiro destas páginas a imediata compreensão da idéia exata que o narrador nos apresenta.

O fascínio que uma narrativa da natureza de $O$ homem que calculava exerce sobre o leitor, certamente está na capacidade que Malba Tahan tem de lidar com conteúdos e lendas que, aos olhos da modernidade refletem um painel de elementos e fatos tão exóticos quanto curiosos. 0 mundo que se desenha nesse romance em nada se aproxima do que o homem moderno conhece e está acostumado. Por esse motivo, parece-nos pertinente afirmar, que, de certo modo, embrenhar nessa aventura é empreender um mergulho agradável na memória de uma civilização que, embora preserve intactos, muitos aspectos de sua cultura, foi descrita habilmente pelo narrador, parceiro fiel de Beremiz - o homem que calculava - num momento especial, configurando-se num belo e astucioso registro de uma época, ao mesmo tempo, remota e significativa.

Se, por um lado, é difícil localizar historicamente o leitor nas trilhas do texto de Malba Tahan, por outro, é igualmente prazeroso falar da aventura que se empreende com a leitura dessa narrativa. O sentimento de nostalgia de um mundo apenas imaginando pelo homem ocidental moderno vem à tona. É um mundo repleto de castelos suntuosos, valiosas obras de artes, autoridades e sábios de toda espécie, sem qualquer sinal dos recursos conhecidos na modernidade. Esses fatores cobrem de interesse o leitor que mergulha nas páginas de $O$ homem que calculava, transportando-se para uma época longínqua, realizando experiência ímpar, carregada de muita aventura e aprendizado. 


\section{Questões de estilo}

Há no estilo literário cultivado em $O$ homem que calculava o que poderíamos chamar de encontro bem sucedido de duas técnicas de composição. Trata-se do modo formal que faz preservar a maneira clássica árabe, pautada pelo esmero na educação, na qual se vê expresso um modo polido adotado pelos interlocutores ao se dirigirem uns aos outros. Este modelo de discurso é que faz transparecer os hábitos mais arraigados da cultura de um povo, em forma de verdadeiro ritual forjado na fala dos personagens protagonistas das cenas principais do romance. Outra técnica adotada, principalmente quando fala o narrador principal do texto de Malba Tahan, é fluente e simples, guardando em si a objetividade da narrativa moderna, dotada do realismo encantador capaz de absorver sem dificuldades o leitor.

A fusão desses dois princípios faz da narrativa em estudo um texto que cumpre a função de nos informar um conjunto de fatos, através de enredo linear e linguagem eficiente, proporcionando-nos uma experiência diferente. A novidade dessa narrativa está exatamente no conjunto: enredo, discurso, espaço, tempo, personagens, temas principais e secundários, partes indissociáveis de um todo coerente.

Dessa forma, podemos afirmar que $O$ homem que calculava apresenta uma espécie de narrativa na qual se percebe a grande força do disfarce caracterizador da linguagem literária. Disfarce esse capaz de promover a transfiguração pelo discurso, ficcionalizando, com singela nobreza, cenas de um cotidiano tão distante do nosso.

A obediência aos preceitos e hábitos do povo árabe, remontando a uma fase remota da história, denota o domínio pleno do autor ao colocar na boca e nos gestos de seus personagens as expressões e formalidades daquele povo. Com isso, Malba Tahan resgata e nos apresenta um estilo diferente de ver e narrar o mundo, adotando em sua narrativa os rituais que seus personagens adotavam em suas vidas, "Em nome de Alá, Clemente e Misericordioso!" (TAHAN, 2005, p. 15), como atesta esta frase inicial de seu romance, invocação ao Deus dos árabes, pedindo sua benção para a empresa que se inicia.

E assim, transcorre toda a narrativa em que as informações, portadoras de inquestionável verossimilhança vão se somando até perfazer um complexo e diversificado universo recheado de vida, completo em atrações, gerando, a cada 
passo grandes expectativa. Cada episódio é uma breve história dentro de uma história maior. E essa grande história se revela num imenso painel, no qual se estampa toda uma cultura cuidadosamente composta, tecido em linguagem engenhosa e eficaz.

O estilo individual de composição em $O$ homem que calculava segue esta tendência moderna desvinculada, de modelos, livre para exercer sua vocação própria. Pode-se dizer que Malba Tahan cultiva um estilo próprio no qual ele apresenta os fatos e expressa a sua visão de mundo. Seu modo de dizer esse mundo a nós apresentada possui, ao mesmo tempo, a leveza meditativa da vida do homem do deserto e o tom solene e grande dos suntuosos palácios de uma aristocracia, cujo bem maior é a tradição.

Sendo assim, parece perfeitamente razoável afirmar que, aliado ao cálculo e à geometria que representa a base temática do romance de Malba Tahan, ele realiza calculada e geometricamente um exercício de linguagem no qual se pode notar o desvelo no peso e nas medidas, tocando de forma sutil em questões como a linguagem poética, cultura popular:

- A saudade e o cálculo andam sempre entrelaçados. Já disse um dos nossos mais inspirados poetas:

A saudade é calculada

por algarismos, também:

distância multiplicada

Pelo fator querer bem. (TAHAN, 2010, p. 188)

Ou mesmo apontando aspectos da relação pacífica entre a matemática ou a ciência em geral com a filosofia, com a poesia, a retórica e outros ramos das humanidades e dos códigos e linguagens, quando cita o poeta árabe Omar Khayyám ou fala do processo de formação de certas línguas como o francês e o inglês, observando certas peculiaridades em seus sistemas numéricos e, consequentemente, no modo de se expressar determinados membros como forma especial de linguagem.

Com esses exercícios de raciocínio Malba Tahan parece romper muitos mitos e conduzir, de maneira gradual num universo fantástico de números, cores, e poesia onde tudo se relaciona e dessa relação nasce a linguagem da superação e da convivência necessária entre as formas e os objetos diferentes. Em outras 
palavras Malba Tahan cultiva, no romance em apreço, um estilo que aproxima os diferentes no gesto decidido de buscar a umidade das coisas na diversidade e no movimento dialético do mundo onde tudo é relativo e os diferentes se complementam.

\section{Elementos textuais}

O que propomos aqui é o levantamento e a qualificação, em termos literários, do gênero de linguagem, da caracterização e o significado dos personagens, bem como a feição principal do tempo, do espaço e da voz narrativa, como partes que compõem um todo, garantindo a sua unidade no romance $O$ homem que calculava de Malba Tahan.

\section{a) Gênero e linguagem}

A riqueza de detalhes, a variação de ambientes, a vida repleta de acontecimentos dos personagens da narrativa de Malba Tahan nos permitem classificá-la como romance, no sentido amplo da palavra.

Dizemos no sentido amplo da palavra porque a forma predominante é a romanesca, mas é necessário salientar que, conforme nos orienta o renomado crítico russo luri Lotman. "O texto artístico não pertence a um único sistema, ou a qualquer tendência única (LOTMAN, 1978, p. 175).

Daí depreende-se a ideia de que, sendo $O$ homem que calculava uma narrativa longa, recheada de células dramáticas (focos de acontecimentos, fatos e ações) variadas, a predominância do gênero romanesco é evidente. Contudo, não se pode esquecer as imagens advindas de construções linguísticas cuidadosamente elaboradas presentes em cada episódio em que se inserem o narrador e o protagonista, seu grande amigo Beremiz Samir.

Há, de fato, no romance de Malba Tahan, uma sequência de pequenos enredos semelhantes a breves contos. Porém esses episódios não podem ser assim classificados pelo fato de estarem todos eles entrelaçados e funcionarem como parte de um grande enredo: as aventuras do homem que calcula, a saga de Beremiz Samir e seu companheiro. 
Poderíamos até chamar essa narrativa de romance de tese, uma vez que, em toda a sua extensão percebe-se a apologia feita pelo protagonista a arte dos cálculos, da matemática em geral. Mas, é preciso observar que, para elogiar a matemática, para humanizá-la e desfazer certos mitos criados em torno dela, o narrador faz, a todo tempo, associações com a "ciência dos números" com outras áreas do conhecimento humano como a filosofia, a psicologia e, principalmente com formas consagradas da arte como a poesia que é a mais recorrente, além de outras.

Diante destas observações uma certeza se evidencia: a tese desenvolvida em O homem que calculava, ao contrário do que se pode imaginar preliminarmente, não é da supremacia da matemática sobre qualquer outra ciência ou categoria da arte e sim, a interdependência entre arte, ciência, religião como forma de se buscar na prática cotidiana os caminhos do conhecimento que conduzem a instância superior da sabedoria.

Ele é, portanto um romance cuja tese fundamental é a de boa convivência entre os diferentes, como se pode observar repetidas vezes os personagens e o narrador citando trechos do livro sagrado dos muçulmanos associando-os a trechos da bíblia cristã, testemunhando ou, pelo menos, sugerindo o exercício da tolerância entre os homens e suas culturas.

Ressalva-se, entretanto, a condição de idólatra, atribuída ao budista pelo crente muçulmano: "Alá se compadeça desse idólatra". (TAHAN, 2005, p. 227).

Com base nessa variedade temática e na riqueza formidável da linguagem e na multiplicidade de pensamentos e ações mentais, além da farta descrição de ambientes, fatos e personagens, sugerindo análise e reflexões acerca do ser e do estar-no-mundo, podemos afirmar tratar-se de um romance o texto em debate de Malba Tahan. E se assim o chamamos, devemos acrescentar a seguinte informação: trata-se de um romance que une a tradição secular ao novo, a ciência à religião; tudo isto, pelo poder mágico de uma linguagem acessível, porém definitivamente profunda e essencialmente meditativa.

\section{b) Dos personagens}

Considerando-se a narrativa de $O$ homem que calculava um conjunto de trinta e quatro pequenos episódios, constituindo cada um deles um breve enredo, en- 
trelaçados entre si; pode-se dizer que a caracterização de seus personagens se dá acompanhando toda essa diversidade de espaços e acontecimentos. Todavia, mesmo contando com uma enorme gama de personagens que vão se somando aos já existentes, em cada novo episódio, Beremiz Samir, o protagonista, juntamente com o bagdali, condutor-mor da narrativa estão sempre presentes no foco principal da história.

Já no primeiro capítulo, temos a explicação de como surgiu a grande amizade entre os dois - narrador-personagem - e protagonista, destacando-se a apresentação de Beremiz Samir, carregada de misticismo; configurando-se muito mais numa análise de sua personalidade eminentemente reflexiva e compenetrada, expondo suas características interiores, deixando de lado qualquer seus traços físicos:

Chamo-me Beremiz Samir e nasci na pequena aldeia de Khói, na Pérsia à sombra da pirâmide de imensa formada pelo Ararat.

Muito moço ainda, empreguei-me, como pastor, a serviço de um rico senhor de Khamat.

[...]Fui, assim, adquirindo, pouco a pouco, tal habilidade em contar que, por vezes, calculava sem erro o rebanho inteiro. Não contente com isso passei a exercitarme contando os pássaros quando, em bandos, voavam, pelo céu afora. Tornei-me habilíssimo nessa arte. (TAHAN, 2010, p. 17)

Como se pode notar no trecho em destaque, o próprio personagem se caracteriza como um homem absolutamente compenetrado e dado, na mesma proporção, aos cálculos, a uma atitude de profunda reflexão permanente, por opção própria.

Antes mesmo dessa apresentação de si mesmo pelo protagonista, o narrador já o havia apresentado previamente no inicio da narrativa, com grande surpresa, pois, ao invés de receber de Beremiz Samir o "salã", cumprimento habitual dos muçulmanos, ouve de sua boca um número vultoso, que muito lhe assusta:

- Um milhão, quatrocentos e vinte e três mi, setecentos e quarenta e cinco!

Sentou-se em seguida e quedou em silêncio, a cabeça apoiada nas mãos, como se estivesse absorto em profunda meditação. (TAHAN, 2010, p. 15) 
Dessa forma, o protagonista é qualificado como uma espécie de monge andarilho que, aliado à ciência dos números se revela portador e grande difusor de um comportamento meditativo, inteiramente voltado para uma tendência que perpassa todo o romance, qual seja, a habilidade de calcular; calcular não só com os números, mas também com a palavra, com a ação. Um personagem que, antes de tudo, semeia a paz exercitando, na prática, a conjunção do espiritual com a racionalidade.

Todos os personagens que se apresentam ao longo de toda a narrativa em questão, têm sua história, de algum modo, atrelada à figura de Beremiz Samir e, a cada novo episódio, sua importância cresce sobremaneira, uma vez que suas façanhas mantêm um clima de ascendência em todo o texto.

Há que se ressaltar também personagens como Ibrahim Maluf, poderoso vizir que valoriza a inteligência de Beremiz, oferecendo-lhe um trabalho como seu auxiliar. A famosa rainha de Sabá, noiva de Salomão, também é lembrada, ao receber de seu noivo um valioso presente: uma caixa contendo 529 pérolas. Uma vez decifradas as suas propriedades pelo homem que calculava, seria revelada toda uma engenhosidade da sabedoria de Salomão. No-Elin aparece na narrativa como grande instrutor de Beremiz, em uma conversa que se estende a outro personagem não menos importante: Euclides, matemático alexandrino, de grande renome entre os árabes, além de Pitágoras e a sua teoria da hegemonia dos números. Sócrates e Sêneca têm seus pensamentos destacados quando o calculista faz reflexões sobre o caráter humano, a retidão. $O$ escritor árabe Gibran Khalil Gibran - que teve sua obra muito difundida e, ainda hoje muito apreciada no mundo inteiro, inclusive no Brasil - faz parte da narrativa, citado pelo calculista ao falar da caridade, a maior virtude humana para os árabes. Maomé e Jesus Cristo aparecem como símbolos dignos de reverência e louvor. Mas, não se pode esquecer em $\mathrm{O}$ homem que calculava a beleza encoberta pelas vestes, mas deslumbrante de Telassim, filha do rei, que teve sua educação confiada a Beremiz e que, mais tarde, torna-se sua esposa e ambos se convertem ao cristianismo.

Todos esses personagens são de elevada importância na vida de Beremiz. Porém, em temos literários, a voz que organiza e nos faz conhecer a todos eles é o narrador que nem se apresenta por um nome. Apenas "o bagdali", maneira pela qual o conhecemos pelas raras vezes em que Beremiz se dirige a ele. Mesmo assim, é importante reiterar o seu significado fundamental para que tudo o que aconteceu viesse a existir de fato, considerando o princípio de que o significado 
das coisas está, por natureza e definição, ligado ao discurso que as fazem tornar visíveis.

\section{c) Do tempo e do espaço}

A narrativa de Malba Tahan se desenvolve com naturalidade e segurança remontando a um tempo e a um espaço que, embora sejam preservados como tradição nos países do Oriente Médio como o Iraque, centro de sua atenção maior, causam grande espanto e encantamento ao leitor dessa obra, pela fluência e originalidade com que são apresentados.

Se considerarmos a tese de que o tempo é o verdadeiro espaço do ser humano, talvez entendamos melhor e mais facilmente a ausência de detalhes nas descrições dos ambientes apresentados por Beremiz e pelo Bagdali (habitante de Bagdá). Podemos notar a nítida preferência e a atenção privilegiada que estes dão à conformação do tempo, elevando-o à condição de grande norteador do romance. Os verbos aparecem, na maioria das vezes, no presente, contudo não se trata do presente atual, mas do presente das ações que Malba Tahan nos transporta com exímia habilidade, fazendo de seu leitor um visitante de outra civilização, com direito de experimentar juntamente com a dupla de andarilhos-narradores as venturas e aventuras pelas quais eles passam.

O tempo é, na verdade, infinito, uma vez que revela todo um aparato cultural de uma civilização: tal qual o espaço se revela num belo quadro provocador de um interesse permanente, posto que traduz toda uma geografia de valor psicológico de valor inestimável.

\section{d) Do foco narrativo}

Não há muito que argumentar sobre o foco narrativo em $O$ homem que calculava. O que nos parece essencial declinar a esse respeito é o fato de que, um narrador onisciente - o bagdali - narra e participa parcialmente dos fatos, todavia sua entrega à ação narrativa é merecedora de destaque. Sua posição na história é a de uma voz que apresenta com justeza os fatos, embora percebamos, de pronto, do seu envolvimento, por afinidade, nas questões em que seu amigo 
Beremiz se envolve. Muito suspense. Eis as situações criadas pelo narrador principal quando um evento desafiador se apresenta para o calculista.

É assim que, grosso modo, é contada a história de Beremiz no terreno do conhecimento, a caminho do saber e de seu amigo, o narrador principal da trama, aventureiro em terras árabes, em tempos que, segundo palavras de Beremiz “...já não mais se percebem através da neblina do passado" (TAHAN, 2005, p. 153), quando fala a sua aluna do fascínio eterno pelos números, base principal da narrativa em apreço.

\section{e) Das artimanhas do autor}

Malba Tahan é, na verdade o pseudônimo de Júlio César de Melo Souza, professor de matemática que sempre demonstrou interesse pela cultura árabe, com mais de quinze livros versando sobre esse tema.

Em verdade, se a biografia do autor pode auxiliar na compreensão de sua obra, O homem que calculava não nega os traços do escritor, professor de matemática e engenheiro civil.

Malba Tahan foi uma ideia bem sucedida de Júlio César de Melo e Souza que passou de personagem a escritor. Andarilho, sempre metido em problemas de matemática, Malba Tahan é uma figura que se repetirá na pele de Beremiz Samir.

Como se pode ver, realidade histórica e ficção se misturam em proporções exatas, tornando deveras agradável a leitura deste brasileiro que viveu 79 anos e foi condecorado com os dizeres sábios do grande escritor e crítico argentino, Jorge Luís Borges, afirmando que a obra de Malba Tahan se enquadra as mais notáveis da humanidade.

\section{Considerações finais}

É preciso, antes de tudo, falar de $O$ homem que calculava como uma leitura diferente e sugestiva. $O$ fato de Júlio César - Malba Tahan - ter feito malabarismos para se apresentar na literatura em um momento em que são parcos os investimentos em editoração, não só no Brasil, mas por todo o mundo, com a crescente ideia de substituição do sentido de fruição da arte para os conceitos 
de consumo, o que deve se considerar os termos custo e benefício, lucros e prejuízos, já é algo que merece atenção.

Destarte, $O$ homem que calculava promove a conjunção bem articulada de um contexto histórico que transporta o leitor para um universo especial, num estilo corrente, inventivo e agradável de ler. É um romance que envolve personagens de várias espécies em um tempo remoto, localizados em local exótico com um narrador de grande fôlego, deixando transparecer sempre muita coerência e humildade. Se é um romance com fortes marcas autobiográficas, esse é um tema que merece novas investigações. No momento, não sabemos até que ponto seria lícito afirmá-lo, porém, é certo que, num tom de elevada intimidade, temos em $O$ homem que calculava uma bela mostra do que se pode chamar de linguagem romanesca, criativa e envolvente, a ponto de chamar a atenção do público jovem, mesmo com suas controvérsias naturais potencializadas pela época de sua aparição no cenário da Literatura, definitivamente um tempo de imprecisões e perda das referências e da solidez nas relações do homem com o homem, com o mundo e com a arte. 


\section{Referências Bibliográficas}

AUERBACH, Erich. Mimesis: A representação da realidade na literatura ocidental. 6a ed. São Paulo: Perspectiva, 2013

BARTHES, Roland. O prazer do texto precedido de Variações sobre a escrita. Tradução de Maria Margarida Barahona, Lisboa, Edições 70, 2009.

BAKHTIN, Mikhail. Questões de Literatura e Estética - a teoria do romance. 70 edição. São Paulo, Editora UNESP-Hucitec, 2014.

BRAIT, Beth. A personagem. 7. ed. São Paulo: Ática, 1999. CANDIDO, Antonio. Noções de análise histórico-literária. São Paulo: Associação

Editorial Humanistas, 2005.

GANCHO, Cândida Vilares. Como analisar narrativas. 7. Ed. São Paulo: Ática: 2000. (Série princípios).

GENETTE, Gérard. Discurso da narrativa. 3. ed. Lisboa: Vega, 1995.REIS, Carlos; LOPES, Ana Cristina M. Dicionário de teoria narrativa. São Paulo: Ática, 2000.

LEITE, Ligia Chiappini Moraes. A tipologia de Norman Friedman. In: O foco narrativo: a polêmica em torno da ilusão. 10. Ed. São Paulo: Ática: 2002. (Série princípios)

LOTMAN, luri. A Estrutura do texto artístico, Coimbra, Editorial Estampa, 1978.

TAHAN, M. O Homem que Calculava. Rio de Janeiro, Record, 2010. 300 p. $79^{\circ}$ ed. 